\title{
APRENDIZAGEM BASEADA EM PROBLEMAS COMO MÉTODO DE ENSINO NA FORMAÇÃO MÉDICA
}

\author{
Maylon Wellik dos Santos Carvalho ${ }^{1}$, Wellen Zane Nunes Andrade ${ }^{2}$, \\ Isaac Farias Cansanção ${ }^{3}$, Maria Augusta Vasconcelos Palácio ${ }^{4}$, Iukary Takenami ${ }^{5}$
}

\section{RESUMO}

As metodologias ativas de aprendizagem, dentre elas a Aprendizagem Baseada em Problemas (ABP), representam um dos principais métodos inovadores de ensino. No entanto, embora diversas Instituições orientem seus cursos pela ABP, a literatura ainda é relativamente recente sobre a percepção do estudante em relação às contribuições e à importância do método. O presente estudo tem por objetivo relatar a experiência discente nas sessões tutoriais da ABP e suas contribuições na formação acadêmica em Medicina. As sessões tutoriais fomentam a formação de alunos críticos, autônomos e participativos, fazendo com que eles assumam a responsabilidade pelo seu aprendizado. Por outro lado, a pressão e o medo de fracassar podem atrapalhar e/ou comprometer o processo de ensino-aprendizagem. É importante destacar que o sucesso do método não é apenas função do educando, mas depende de outros fatores que incluem aceitação do método pelo discente, proatividade do tutor, infraestrutura, situação-problema bem elaborada e outros elementos que devem ser considerados na sua implementação.

Palavras-chave: Aprendizagem Baseada em Problemas. Ensino-aprendizagem. Metodologias ativas. Ensino superior. Educação médica. Estudante de Medicina.

\section{Como citar este documento - ABNT}

CARVALHO, Maylon Wellik dos Santos et al. Aprendizagem baseada em problemas como método de ensino na formação médica. Revista Docência do Ensino Superior, Belo Horizonte, v. 10, e019801, p. 1-21, 2020. DOI: https://doi.org/10.35699/2237-5864.2020.19801.

Recebido em: 30/03/2020 Aprovado em: 08/05/2020 Publicado em: 31/08/2020

\footnotetext{
${ }^{1}$ Universidade Federal do Vale do São Francisco (UNIVASF), Paulo Afonso, BA, Brasil. ORCID ID: https://orcid.org/0000-0003-3659-4894. E-mail: mwscmedicina@outlook.com. ${ }^{2}$ Universidade Federal do Vale do São Francisco (UNIVASF), Paulo Afonso, BA, Brasil. ORCID ID: https://orcid.org/0000-0003-1449-1245. E-mail: wellenzandrade@gmail.com. ${ }^{3}$ Universidade Federal do Vale do São Francisco (UNIVASF), Paulo Afonso, BA, Brasil. ORCID ID: https://orcid.org/0000-0003-2125-9866. E-mail: isaac.farias@univasf.edu.br. ${ }^{4}$ Universidade Federal do Vale do São Francisco (UNIVASF), Paulo Afonso, BA, Brasil. ORCID ID: https://orcid.org/0000-0002-2780-125X. E-mail: augusta.palacio@univasf.edu.br. ${ }^{5}$ Universidade Federal do Vale do São Francisco (UNIVASF), Paulo Afonso, BA, Brasil. ORCID ID: https://orcid.org/0000-0001-5660-7766. E-mail: iukary.takenami@univasf.edu.br.
} 


\section{APRENDIZAJE BASADO EN PROBLEMAS COMO MÉTODO DE ENSEÑANZA EN LA FORMACIÓN MÉDICA}

\section{RESUMEN}

Las metodologías de aprendizaje activo, entre ellas el aprendizaje basado en problemas (ABP), representan uno de los principales métodos de enseñanza innovadores. Sin embargo, aunque varias instituciones guían sus cursos por $A B P$, la literatura aún es relativamente reciente sobre la percepción del alumno en relación con las contribuciones y la importancia del método. El presente estudio tiene como objetivo informar la experiencia del estudiante en las sesiones de tutoría de ABP y sus contribuciones a la formación académica de la medicina. Las sesiones de tutoría fomentan la formación de estudiantes críticos, autónomos y participativos, asumiendo la responsabilidad de su aprendizaje. Por otro lado, la presión y el miedo al fracaso pueden obstaculizar y/o comprometer el proceso de enseñanza-aprendizaje. Es importante destacar que el éxito del método no es solo responsabilidad del alumno, sino otros factores que incluyen la aceptación del método por parte del alumno, la proactividad del tutor, la infraestructura, la situación problemática bien desarrollada y otros elementos que deben considerarse en su implementación.

Palabras clave: Aprendizaje Basado en Problemas. Enseñanza-aprendizaje. Metodologías activas. Enseñanza superior. Educación médica. Estudiante de Medicina.

\section{PROBLEM-BASED LEARNING AS A TEACHING METHOD IN MEDICAL TRAINING}

\section{ABSTRACT}

Active learning methodologies, such as Problem Based Learning (PBL), represent one of the main innovative teaching methods. However, although several institutions usually guide their courses through PBL, studies on the student's perception about the importance and contribution of the method are still relatively recent. The present study aims to report the student experience in the tutorial sessions of the PBL and their contributions to academic training in Medicine. The tutorial sessions foster the training of critical, autonomous and participatory students, making them take responsibility for their learning. On the other hand, pressure and fear of failure can hinder and/or compromise all the teaching-learning process. It is important to highlight that the success of the method is not just the student's function, but rather depends on other factors that include: acceptance of the method by the student; proactivity of the tutor; infrastructure; a well-developed problem situation, and other elements that must be considered in its implementation.

Keywords: Problem-Based Learning. Teaching-learning. Active methodologies. Higher education. Medical education. Medicine student. 


\section{INTRODUÇÃO}

As Tecnologias de Informação e Comunicação (TIC) são responsáveis, em grande parte, pelas transformações econômicas, políticas e culturais da sociedade contemporânea. Elas influenciam diretamente o modo como os indivíduos interagem, aprendem e percebem o mundo, abrindo novas perspectivas no que se refere ao acesso e à aquisição de conhecimento (PIMENTEL, 2016). Todavia, paralelamente a essas transformações, as relações recíprocas entre educação e sociedade não mais se sustentam e, consequentemente, observa-se nos últimos anos uma ruptura das práticas pedagógicas nas Instituições de Ensino Superior (IES) públicas e privadas (CEZAR et al., 2010).

A facilidade de acesso à informação, provida pela cultura digital e pelas ferramentas tecnológicas, oferece ao discente a oportunidade de aprender em qualquer lugar e a qualquer hora. Nesse contexto, o método tradicional de educação, pautado em aulas expositivas, não é mais suficiente para fornecer uma aprendizagem duradoura e sólida entre os educandos (FARIAS; MARTIN; CRISTO, 2015). Assim, a busca por novos modelos de produção e organização de conhecimento, condizentes com as demandas e necessidades da sociedade atual, coincide com o novo currículo proposto pelas Diretrizes Curriculares Nacionais (DCN) do curso de graduação em Medicina (BRASIL, 2014).

As novas DCN, revisadas e reformuladas em 2014, enfatizam a preocupação de formar médicos generalistas com desenvolvimento de competências e habilidades que permitam uma maior aptidão em trabalhar com as necessidades reais da população, especialmente com ênfase na adequação às demandas do Sistema único de Saúde (SUS). Diante desse cenário, o emprego dessas novas metodologias sustenta a ideia de que, na sociedade atual, não cabe mais ao docente o papel de detentor do conhecimento e do saber e que, portanto, promover a autonomia do discente na resolução de situações-problema deve ser prioridade no método de ensino (BERBEL, 2011).

Dentre as metodologias ativas de aprendizagem preconizadas pelas $\mathrm{DCN}$, destaca-se a Aprendizagem Baseada em Problemas (ABP), do inglês Problem Based Learning (PBL). Este método permite ao estudante investigar, analisar, debater e propor soluções pertinentes à prática médica, por meio do trabalho colaborativo. Na atualidade, a ABP funciona como eixo indissociável do aprendizado teórico, promovendo a interdisciplinaridade e integralidade na formação dos discentes (CEZAR et al., 2010; DIESEL; BALDEZ; MARTINS, 2017).

A precursora do modelo da ABP foi a McMaster University, no Canadá, no final dos anos de 1960. Desde então, o método foi redesenhado e instituído na Harvard Medical School, em 1985. Somente a partir da década de 1990 que a ideia ganhou corpo, força e chegou ao Brasil por meio da Faculdade de Medicina de Marília (FAMEMA) e pela Universidade Estadual de Londrina (UEL) (MILLAN et al., 2012). Atualmente, muitas escolas médicas já 
utilizam a ABP como método central de ensino no currículo médico. No Nordeste, aproximadamente $78 \%$ das instituições médicas empregam algum tipo de metodologia ativa (TAKENAMI et al., 2018), incluindo a ABP. Uma das IES que emprega a ABP como método de ensino é a Universidade Federal do Vale do São Francisco (UNIVASF), campus Paulo Afonso, Bahia. O curso de graduação em Medicina nesse campus surgiu a partir da iniciativa do Governo Federal de expandir a oferta do ensino médico (OLIVEIRA et al., 2019). Desde a sua abertura em 2014, aproximadamente 40 vagas são ofertadas em turno integral em um regime acadêmico anual. Na referida instituição, dois campi ofertam o curso de Medicina. No entanto, buscando atender às novas DCN, o campus de Paulo Afonso utiliza a ABP como prática pedagógica central na organização curricular do 10 ao 8 o semestre (UNIVERSIDADE FEDERAL DO VALE DO SÃO FRANCISCO, 2017). Ademais, esse é o primeiro curso da instituição a utilizar as metodologias ativas de aprendizagem como método de ensino e, portanto, representa um laboratório prático e teórico de saberes docente e discente.

Seis anos após a atualização das DCN, muitos estudos já foram publicados com o objetivo de compreender a importância da ABP na formação dos alunos do curso de Medicina (MORAES; MANZINI, 2006; GOMES et al., 2009). No entanto, no Brasil, a literatura ainda é relativamente recente e poucos são os estudos que enfatizam e destacam a percepção e nível de satisfação desses estudantes (GOMES; REGO, 2011; IGARASHI; HAMAMOTO; SANTOS 2018). O estudo publicado por Smolka, Gomes e Siqueira-Batista (2014) revelou boa receptividade e adaptação ao método, incluindo maior autonomia e participação ativa do discente. Nessa perspectiva, entende-se que a visão do estudante sobre o método de ensino é de fundamental importância, pois permite oferecer uma orientação mais qualificada e um melhor uso dos recursos educacionais, garantindo um resultado mais expressivo no processo de ensino-aprendizagem. Assim, o objetivo deste estudo é relatar a experiência de dois educandos nas sessões tutoriais da ABP e seus reflexos na formação acadêmica de Medicina.

\section{METODOLOGIA}

Trata-se de um estudo descritivo, um relato de experiência vivenciado por dois discentes (D1, D2) de graduação em Medicina da Universidade Federal do Vale do São Francisco (UNIVASF), campus Paulo Afonso. O relato compreende o período de setembro de 2016 (10 semestre) a agosto de 2019 (6@ semestre), totalizando três anos de experiência com a aplicação da ABP. O campus homenageia o município com mesmo nome e está localizado no interior do estado da Bahia, em uma ilha artificial banhada pelo Rio São Francisco, fazendo fronteira com os estados de Pernambuco, Alagoas e Sergipe. Essa localização privilegiada permite uma pluralidade de estudantes oriundos de diversos estados.

A ABP aplicada nessa instituição consistiu em uma abordagem fortemente sistematizada para a resolução de problemas, mediante a aplicação de passos e sequências pré- 
estabelecidas em um roteiro adaptado do trabalho publicado por Mamede e Penaforte (2001). A utilização do método ocorreu em dois momentos presenciais (abertura e fechamento), os quais foram intitulados sessões tutoriais e ocorreram semanalmente ao longo de um semestre. As sessões foram compostas por, no máximo, 12 alunos e um docente tutor. A cada sessão tutorial, um discente coordenador e um discente secretário eram definidos, por indicação do docente tutor ou por livre escolha do aluno. De modo que, ao longo do semestre, ocorreu um revezamento dos papéis de coordenador e secretário entre o grupo de estudantes.

Após essas definições, o docente tutor entregava a todos a situação-problema. Os educandos analisavam, discutiam e propunham resolução para cada uma das situaçõesproblema abordadas em cada período do curso. Foram trabalhadas, por semestre, aproximadamente 13 situações-problema pertinentes aos conhecimentos teóricos e práticos da formação médica. Os elementos, participantes e o passo a passo da sessão tutorial são descritos na Figura 1 e no Quadro 1, respectivamente.

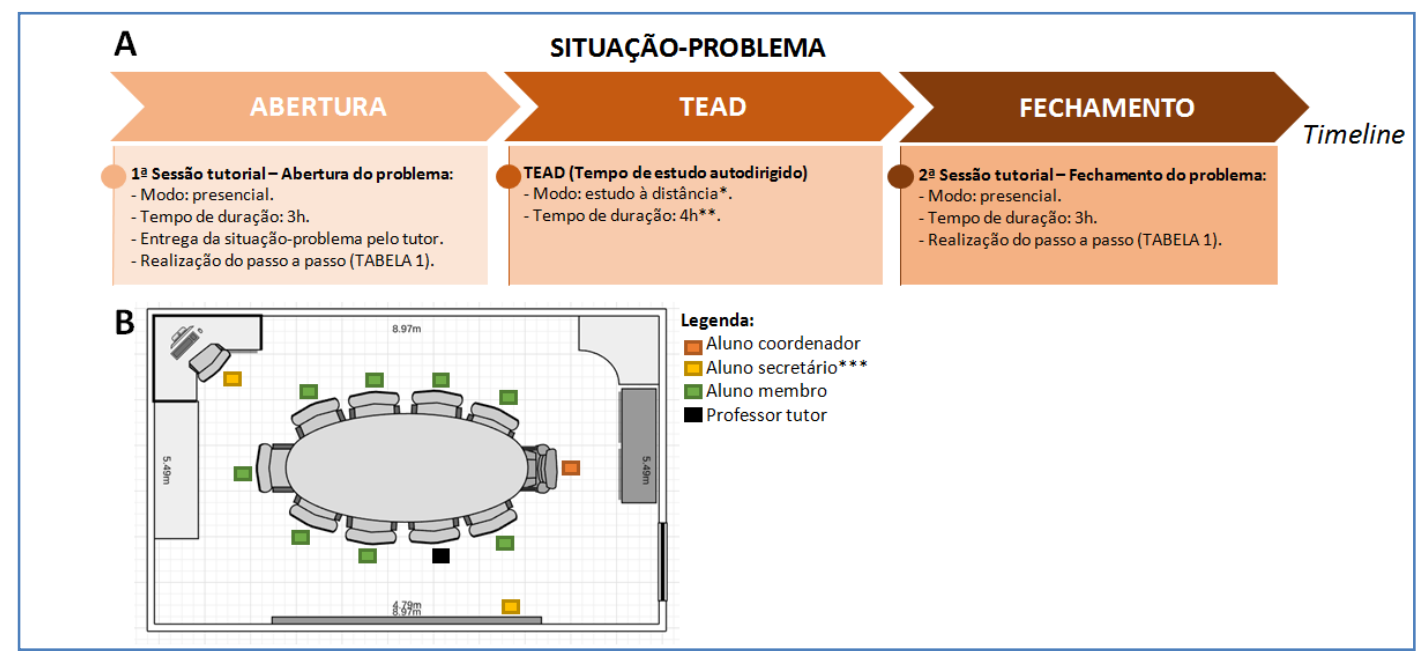

Figura 1 - Timeline da aplicação (A) e participantes (B) da Aprendizagem Baseada em Problemas (ABP)

*O TEAD pode ser realizado em qualquer espaço da universidade e/ou no próprio domićlio do aluno.

** O TEAD depende das particularidades de cada discente. No entanto, na grade curricular disponibiliza-se o período de 4 horas semanais para realização do TEAD.

***O aluno secretário poderá participar utilizando o computador com o datashow, quadro branco ou lousa digital.

Fonte: elaborada pelos autores, 2019.

As situações-problema trabalhadas representavam situações autênticas ou aplicáveis, criadas a partir da prática profissional e/ou doenças prevalentes no SUS. Foram utilizados textos, figuras e vídeos como recursos de suporte na atuação do educando. Os problemas foram cuidadosamente elaborados e/ou revisados pelos tutores, de tal forma que as temáticas presentes neles orientaram e direcionaram os alunos na construção dos objetivos 
e, portanto, no conteúdo a ser estudado. Dessa forma, as questões apresentadas nas sessões tutoriais foram inerentes aos conteúdos da matriz curricular do 1을 a 3 으 ano do curso de graduação em Medicina da UNIVASF (UNIVERSIDADE FEDERAL DO VALE DO SÃO FRANCISCO, 2017).

\begin{tabular}{|c|c|c|}
\hline $\begin{array}{l}\text { Sessão } \\
\text { Tutorial }\end{array}$ & Passo & Significado \\
\hline \multirow{7}{*}{$\begin{array}{l}\text { 1a Sessão } \\
\text { Tutorial - } \\
\text { Abertura do } \\
\text { problema }\end{array}$} & 10 Passo & $\begin{array}{l}\text { Ler atentamente o problema (individualmente e em grupo); } \\
\text { identificar e esclarecer os termos desconhecidos. }\end{array}$ \\
\hline & 2o Passo & Identificar as temáticas propostas pelo problema. \\
\hline & 3ㅇ Passo & $\begin{array}{l}\text { Levantar conhecimentos prévios sobre as temáticas identificadas, } \\
\text { promovendo uma chuva de ideias, do inglês brainstorming. }\end{array}$ \\
\hline & 4으 Passo & Elaborar a síntese da chuva de ideias ( 1 a 3 orações). \\
\hline & 5으 Passo & Estabelecer os objetivos de aprendizagem. \\
\hline & 60 Passo & $\begin{array}{l}\text { Feedback da abertura: avaliação individual e avaliação interpares } \\
\text { (coordenador, secretário, demais discentes e o tutor - docente). }\end{array}$ \\
\hline & 7으 Passo & $\begin{array}{l}\text { Estudo individual respeitando os objetivos estabelecidos: Tempo } \\
\text { de Estudo Autodirigido (TEAD). }\end{array}$ \\
\hline \multirow{7}{*}{$\begin{array}{l}\text { 2a Sessão } \\
\text { Tutorial - } \\
\text { Fechamento } \\
\text { do problema }\end{array}$} & 10 Passo & Reler o problema (leitura em grupo). \\
\hline & 2ㅇ Passo & Definir a ordem da discussão dos objetivos, caso seja necessário. \\
\hline & 3으 Passo & $\begin{array}{l}\text { Apresentar as referências bibliográficas para cada objetivo de } \\
\text { aprendizagem.* }\end{array}$ \\
\hline & 4ㅇ Passo & Discutir os objetivos estudados. \\
\hline & 5으 Passo & Leitura dos objetivos propostos pelo tutor. \\
\hline & 60 Passo & $\begin{array}{l}\text { Identificar objetivos não alcançados e definir um plano de } \\
\text { pendências. }\end{array}$ \\
\hline & 70 Passo & $\begin{array}{l}\text { Feedback do fechamento: avaliação individual e avaliação } \\
\text { interpares (coordenador, secretário, demais discentes e o tutor - } \\
\text { docente). }\end{array}$ \\
\hline
\end{tabular}

Quadro 1 - Passos da sessão tutorial da ABP aplicada no curso de graduação em Medicina da UNIVASF, campus Paulo Afonso

*As referências podem ser apresentadas antes de se discutir cada objetivo, de tal forma que os alunos possam elencar determinada referência ao seu respectivo objetivo.

Fonte: elaborado pelos autores, 2019.

\section{RESULTADOS E DISCUSSÃO}

Este relato apresenta a experiência e as percepções, pautadas nas observações in loco, de dois discentes (D1, D2) do curso de graduação em Medicina. A cada semestre um novo tutor com formação na área de Saúde era designado ao grupo. Isso permitiu o contato com diferentes profissionais com formações nas áreas de Biologia, Biomedicina, Enfermagem, Medicina e Odontologia. Os tutores tinham como nível de escolaridade mais elevado o doutorado (62,5\%) ou pós-doutorado (12,5\%). Dos 12 tutores (um por semestre) envolvidos na formação dos dois discentes, apenas um (12,5\%) era graduado em Medicina, cuja titulação máxima era especialista. A distribuição dos estudantes seguiu um rodízio, o que permitiu a eles se conhecerem e se aproximarem da classe ao longo desses três anos de 
curso. O número mínimo e máximo de alunos que compôs as sessões tutoriais foi de 8 e 12 sujeitos, respectivamente.

\section{A chegada: imersão nas metodologias ativas de aprendizagem}

As metodologias ativas de aprendizagem foram integradas ao curso de Medicina a partir das DCN de 2014 (BRASIL, 2014), porém poucos são os educandos que conhecem o método e/ou foram formados por meio dele na educação básica. Após o ingresso na IES, a principal expectativa do discente refere-se ao ajustamento no ambiente universitário. Na maioria das vezes, esse ajustamento envolve aspectos multidimensionais, os quais incluem: mudança de município, distanciamento do núcleo familiar e do grupo de amigos, entre outros (SOUZA; FRANCO, 2018). Devido a esses fatores, é comum o aluno não se interessar e/ou pesquisar sobre o método de ensino da IES, que pode representar um grande desafio ou até mesmo impor uma limitação aos estudantes em seu desenvolvimento cognitivo, uma vez que não conseguem adaptar-se rapidamente às metodologias ativas de aprendizagem. Corroborando esses achados, um estudo publicado por Igarashi, Hamamoto e Santos (2018) demonstrou que, na Faculdade de Medicina de Marília (FAMEMA), os alunos, ao compararem o método utilizado na Unidade Educacional Sistematizada (UES) com o método de ensino tradicional, apresentaram uma maior fragilidade na compreensão da ABP, base para a UES.

Essas dificuldades mostram também reflexos do domínio dos métodos tradicionais de ensino na formação pré-acadêmica do estudante, formação esta ligada à aprendizagem passiva, centrada no docente e na transmissão do conhecimento (MAMEDE; PENAFORTE, 2001). Sendo assim, muitas vezes, o sujeito chega na IES sem conhecimento prévio da metodologia abordada no curso de Medicina, o que intensifica o estranhamento frente à $A B P$ e a morosidade em relação à adaptação. As dificuldades encontradas ficam claras em uma fala de uma aluna de Medicina de uma faculdade particular de Minas Gerais: "A gente vem também assim de uma cultura de não ter estudos desse tipo. A gente está acostumada com pessoas dando aula e a gente só recebendo informação" (TEIXEIRA; ALMEIDA; AGUILAR-DASILVA, 2018, p. 23). Ademais, um estudo publicado por Torres, Sampaio e Caldeira (2019) sugere ainda que a imaturidade inerente à tenra idade pode também contribuir para a dificuldade de adaptação ao novo método de ensino.

Na contramão desse pensamento, o ingresso na UNIVASF, mediante transferência de curso entre universidades federais, foi objeto de escolha do discente $D 1$, justamente pela inovação no método de ensino, ao empregar as metodologias ativas no currículo de Medicina. Essa escolha foi fomentada por informações coletadas de outras IES, sites, relatos de experiência de docentes, estudantes, entre outros. Por outro lado, o discente D2 não tinha conhecimento sobre as metodologias ativas e isso representou uma surpresa e um grande desafio, visto que até então nenhum contato prévio havia ocorrido com essa forma de 
ensino-aprendizagem. Ainda que tenha havido resistências, durante as primeiras semanas de aula os questionamentos e dúvidas ganharam força e voz, deixando de ser apenas incertezas. Para saná-los, a instituição promoveu a Semana do Calouro que, dentre outras atividades, realizou um diálogo entre veteranos, professores e coordenação para apresentar a estrutura curricular e o método de aprendizagem trabalhado no curso de Medicina.

\section{A ABP sendo integrada à formação do discente universitário}

Embora na teoria a ABP seja de fácil entendimento, na prática não foi simples compreendêla e/ou adaptar-se a ela, especialmente para os estudantes que já estavam acostumados com a aula expositiva tradicional, realidade que permeia a grande maioria das escolas de ensino médio (SOUZA; DOURADO, 2015). O primeiro contato prático com a ABP ocorreu mediante uma simulação da sessão tutorial, realizada ainda na primeira semana de aula, cujo título foi “Problema 0: Aprendizagem Baseada em Problemas, e agora?". Essa simulação seguiu os passos da ABP aplicada na instituição e, como forma de ambientalizar o aluno ao método, dois veteranos foram convidados a participar da simulação como coordenador e secretário. Além destes, o tutor docente também participou como facilitador do processo de aprendizagem. Ainda que a simulação tenha sido importante para vislumbrar o método, o passo a passo da sessão tutorial e sua importância só foram de fato compreendidos com a repetição da $A B P$ ao longo do 10 semestre.

A ABP é uma metodologia que quebra paradigmas e conceitos, pois desconstrói a ideia de que o docente é o centro do processo de ensino-aprendizagem e transfere essa posição para o discente (MACEDO et al., 2018). Nesse tipo de metodologia, o professor se posiciona como mediador entre o conhecimento e os estudantes e, portanto, estes são orientados a construir de forma ativa o seu conhecimento, juntamente com os interpares que os acompanham nesse processo (DIESEL; BALDEZ; MARTINS, 2017). Assim, é plausível considerar que a ABP é um método formativo, e não meramente informativo como as práticas pedagógicas tradicionais, pois estimula uma atitude ativa do aluno em busca do conhecimento (SAKAI; LIMA, 1996). Segundo Berbel (1998), várias escolas médicas no Brasil estudavam adotar a ABP como método de ensino em seus currículos mesmo antes da publicação das DCN do curso de graduação em Medicina de 2001 (BRASIL, 2001), o que demonstra que a busca por novos modelos de produção e organização do conhecimento já era desde então uma demanda presente.

No 1 o semestre, a ABP foi um dos grandes obstáculos para os educandos na vivência acadêmica, visto que houve muitos questionamentos sobre qual o nível de aprofundamento adequado frente ao conteúdo. Além disso, por se tratar de um grupo heterogêneo, os alunos apresentaram dificuldades em adentrar nas discussões e, consequentemente, observou-se uma polarização na discussão por dois ou três estudantes. No entanto, com o passar dos 
semestres, as relações de convivência construídas e a familiarização com o método permitiram uma participação mais ativa e equânime entre eles. O mesmo pôde ser observado por Torres, Sampaio e Caldeira (2019), que perceberam um elevado grau de dificuldades, incertezas e angústias, trazidas pelos estudantes que ingressam nas metodologias ativas. Somam-se a esses obstáculos, dúvidas quanto à fonte e/ou base de dados que deverá ser utilizada na busca do conhecimento. Em conjunto, essas conclusões ratificam que, ao ingressar na IES, os discentes não estão totalmente preparados para exercer a autonomia requerida pelo método.

\section{Impactos da ABP na formação discente e profissional}

Segundo Gomes e Rego (2011), há poucas experiências de aferição de resultados de mudanças curriculares no Brasil especificamente voltados aos impactos da ABP segundo a perspectiva discente, sendo encontrados com mais facilidade trabalhos internacionais que tratem dessa temática. Entretanto, alguns estudos que avaliaram a ABP e as concepções tanto dos docentes quanto dos educandos sobre ela foram realizados na Faculdade de Medicina de Marília (FAMEMA), que desde 1997 iniciou um processo de implementação da $A B P$ em seu currículo. O primeiro estudo atesta que o contexto de ensino-aprendizagem e da prática profissional é dinâmico e cheio de contradições e opiniões diferentes, e que:

Esses estudantes mostraram, com tais sentimentos, a não compreensão dos papéis dos docentes neste currículo e método de ensino-aprendizagem, o que ainda poderia revelar a necessidade de maior capacitação dos docentes nos novos papéis (MORAES; MANZINI, 2006, p. 129).

O segundo estudo relatou a experiência da Unidade Educacional do Sistema Endocrinológico (UESE), que aconteceu durante o segundo semestre do curso médico da FAMEMA. Os comentários feitos nas avaliações da unidade demonstraram a necessidade de maiores reflexões sobre os passos do processo tutorial por parte dos alunos e dos tutores, apontando que a ABP apresenta tanto conquistas como fragilidades, mas que o paradigma biologicista da Medicina deve ser a cada dia rompido (TSUJI; AGUILAR-DA-SILVA, 2004).

O estudo de Costa et al. (2011) mostrou que a incorporação das metodologias ativas no currículo médico estimulou a aprendizagem e promoveu uma boa aceitação entre os discentes do Centro Universitário Serra dos Órgãos (UNIFESO - RJ). Conforme os autores, os educandos optaram por estudar na instituição, principalmente, diante das boas referências no ensino médico. Embora essa escolha não tenha sido pautada na mudança de currículo, 0 estudo apresentou resultados positivos em relação à percepção dos estudantes sobre a $A B P$, porém indicou também que melhorias nas metodologias ainda eram necessárias. Por outro lado, um estudo realizado por Millan et al. (2012) mostrou que os alunos do currículo 
tradicional julgaram-se mais bem preparados nos aspectos sociais da doença, habilidades médicas e conceitos éticos do que aqueles submetidos à ABP.

Em relação ao curso de Medicina da UNIVASF, campus Paulo Afonso, a cada situaçãoproblema foi escolhido entre os alunos da sessão tutorial um coordenador e um secretário, ambos com funções pré-definidas. De acordo com Mamede e Penaforte (2001), são funções do coordenador orientar os colegas na discussão do problema, segundo os passos da sessão tutorial, favorecendo a participação de todos e mantendo o foco nas discussões; desestimular a monopolização ou a polarização das discussões; apoiar as atividades do secretário e respeitar as posições individuais, garantindo que estas sejam discutidas pelo grupo com seriedade; exigir que os objetivos do aprendizado sejam apresentados pelo grupo de forma clara, objetiva e compreensível e solicitar auxílio do tutor, quando pertinente. Por outro lado, são funções significativas do secretário deixar registradas as discussões e os eventos ocorridos em cada sessão tutorial, de modo a facilitar a leitura posterior que será feita pelos membros do grupo; anotar com rigor os objetivos de aprendizagem e respeitar as opiniões do grupo.

Todos os membros da sessão tutorial revezaram nas funções de coordenador e secretário, de maneira que, ao longo do semestre, cada estudante foi coordenador e secretário, pelo menos uma vez. Isso permitiu que todos compreendessem na prática a função e a importância de cada um deles no processo de ensino-aprendizagem. Além disso, a cada início de semestre, um novo rodízio de discentes era realizado. Buscou-se durante a formação dos grupos equilibrar o quantitativo de alunos quanto aos possíveis conflitos de interesse e às repetências. O objetivo foi estruturar o grupo de maneira a ampliar a equidade e a produtividade, uma vez que as experiências e vivências dos estudantes poderiam beneficiar e/ou prejudicar algum grupo de tutoria. A diversidade na formação dos grupos contribuiu para o desenvolvimento de um trabalho colaborativo e cooperativo, bem como para a capacitação dos educandos no enfrentamento de adversidades, sobretudo porque as pessoas possuem personalidades singulares e podem carregar diferentes conhecimentos prévios relacionados ao problema. Essa heterogeneidade estimula a capacidade de saber ouvir, respeitar a opinião dos outros e expressar suas ideias de maneira amistosa. Na prática profissional, essa estratégia visa a formação de profissionais capazes de atuar e comunicar-se adequadamente com os colegas de trabalho, equipe multiprofissional, pacientes e familiares, de forma a prover uma melhor atenção à saúde (GOMES et al., 2009; SOUZA; DOURADO, 2015).

As sessões tutoriais da ABP ocorreram às terças-feiras (abertura da situação-problema) e às segundas-feiras da semana seguinte (fechamento da situação-problema), independentemente do semestre. Esse intervalo de uma semana entre a abertura e o fechamento possibilitou ao discente tempo suficiente para planejar e organizar seu 
cronograma de estudo, sendo sempre resguardado o tempo mínimo necessário para o estudo individual - Tempo de Estudos Autodirigidos (TEAD).

Após a definição do coordenador e do secretário, os problemas eram distribuídos e procedia-se o início da abertura da sessão tutorial. Dentre as etapas pertinentes à 1a sessão, destaca-se a chuva de ideias (do inglês, brainstorming), 3 passo da abertura do problema (QUADRO 1). Embora todas as etapas sejam importantes, a chuva de ideias foi uma etapa imprescindível para o processo de ensino-aprendizagem dos respectivos discentes. As diferentes experiências e vivências permitiram aos estudantes ressignificar as situaçõesproblema, estabelecendo conexões e aumentando a compreensão quanto à complexidade do mundo que os cerca. Portanto, nesse momento, foram motivados a fazer conexões, expressar e/ou achar pressupostos relacionados ao problema, foi o momento para o "erro não intencional" e do "achismo" relativo a diversos conteúdos abordados.

Durante essa etapa, a atuação do tutor como mediador foi de extrema importância. As perguntas norteadoras realizadas pelos docentes estimularam o processo crítico-reflexivo coerente com a proposta do método (BOROCHOVICIUS; TORTELLA, 2014). Em cada semestre, os tutores ouviram atentamente a chuva de ideias, realizaram perguntas dirigidas para explorar e/ou estimular o pensamento dos discentes. Em seguida, procedeu-se a síntese e construção dos objetivos. Entre a abertura e o fechamento realizou-se o TEAD. Neste momento, o sujeito foi capaz de identificar suas necessidades de estudo e, portanto, criou o seu próprio método para absorver o conteúdo. Era muito comum o aluno lembrar do "erro não intencional" e substituí-lo pelo conhecimento fundamentado em bons argumentos, com bases sólidas e cientificamente comprovados. Essa organização tutorial (abertura - TEAD - fechamento) tem uma importância significativa no preparo do profissional médico, visto que, para atuar em diferentes situações na rede de saúde, seja ela pública ou privada, o profissional necessita desenvolver autonomia e capacidade de gestão.

A crescente autonomia, concedida ao discente pelo docente tutor, permitiu àquele estimular o pensamento crítico-reflexivo, criar os objetivos de aprendizagem a serem alcançados e a buscar por conta própria referências bibliográficas atualizadas e pertinentes em relação à situação-problema. Em conjunto, essas ações contribuem para a aquisição de conhecimento e fortalecimento do processo de interdependência. No que diz respeito ao profissional médico, essa autonomia repercute na identificação, análise e interpretação dos problemas da prática médica e na sua resolução, assim como na utilização adequada de procedimentos diagnósticos e terapêuticos, validados e comprovados cientificamente. Esse resultado só ocorre porque as discussões a respeito da formação médica vêm repensando as metodologias de ensino no sentido de adaptá-las e torná-las favoráveis ao perfil do profissional que se quer formar (GOMES et al., 2009). Além disso, a administração e o gerenciamento promovidos pela atuação do secretário e, individualmente, pela organização 
do TEAD, fomenta a formação de profissionais aptos a fazer o gerenciamento e a administração tanto da força de trabalho, recursos físicos e materiais, quanto da produção intelectual e científica.

Durante as sessões tutoriais de fechamento, todos os alunos eram estimulados a discutir e relembrar as informações discutidas na chuva de ideias e, quando necessário, a realizar as devidas correções. Ao final desse processo, os tutores realizavam a leitura dos objetivos oficiais e, caso algum objetivo não fosse contemplado, este entrava como pendência para a próxima sessão tutorial. A complexidade dos problemas aumentava a cada semestre, bem como oportunizava ao estudante rever temáticas em diferentes níveis de profundidade. De acordo com Moran (2018, p. 2), "a aprendizagem é ativa e significativa quando avançamos em espiral, de níveis mais simples para mais complexos de conhecimento e competência em todas as dimensões da vida". Em conjunto, os discentes se percebem construtores de sua aprendizagem, capazes de aprender a aprender. Isto é, identificam conhecimentos prévios, desenvolvem a curiosidade, formulam questões para a busca de respostas cientificamente consolidadas e avaliam criticamente as informações obtidas nos diferentes tipos de fontes.

Embora o nível de dificuldade das situações-problema, ao longo dos semestres, fosse cada vez mais complexo, a compreensão e o entendimento foram fatores que influenciaram a ausência de pendências. A construção das situações-problema era realizada pelos docentes tutores com base nos problemas pertinentes à população brasileira e/ou local. Desse modo, os problemas promoviam a integração e a interdisciplinaridade em coerência com o eixo de desenvolvimento curricular, buscando integrar as dimensões biológicas, sociais, psicológicas e ambientais. Além disso, buscou-se utilizar diferentes cenários de ensino-aprendizagem permitindo ao aluno conhecer e vivenciar situações variadas de vida, da organização da prática e do trabalho em equipe multiprofissional. Moran também concorda que

a aprendizagem ativa aumenta a nossa flexibilidade cognitiva, que é a capacidade de alternar e realizar diferentes tarefas, operações mentais ou objetivos e de adaptar-nos a situações inesperadas, superando modelos mentais rígidos e automatismos pouco eficientes (MORAN, 2018, p. 3).

Por fim, ressalta-se a importância da realização de feedback ao final da abertura e do fechamento das sessões tutoriais. Inicialmente, o feedback era visto como um elemento programado, que não necessitava de muita atenção por parte dos discentes. No entanto, ao longo dos semestres, passou a ser considerado um elemento importante na construção do conhecimento. É por intermédio dele que o docente tutor, discente coordenador, discente secretário e demais membros da sessão tutorial exprimem uma retroalimentação sobre o problema e sobre o seu papel enquanto tutor, coordenador, secretário e membro da sessão tutorial. Essa crítica construtiva foi um instrumento primordial para o crescimento e melhorias no processo de ensino-aprendizagem do estudante. Atualmente esse retorno é visto como imprescindível na aplicação da $A B P$, pois permite o amadurecimento individual e 
coletivo mediante avaliação de habilidades e desempenho, identificando pontos fortes e os que precisam ser melhorados. Esta capacidade de receber e fazer autocríticas construtivas permite que o profissional exerça de forma mais qualificada o serviço de atenção e cuidado à saúde. Nesse sentido, ele encontra-se mais preparado para identificar deficiências e, consequentemente, possibilitar reformulações e aperfeiçoamento no seu trabalho e no desenvolvimento de ações futuras.

\section{Infraestrutura da ABP}

A infraestrutura de uma sala de tutoria é bem diferente daquela de uma sala tradicional, porém adequada para que os estudantes sejam mais participativos. A sala de tutoria é composta basicamente por uma mesa circular e, no máximo, 13 cadeiras dispostas ao redor da mesa. Essa configuração permite conforto e horizontalidade no discurso, sobretudo com o tutor, que se equipara à figura do discente. Além disso, desperta responsabilidade, segurança, autonomia e satisfação por compartilhar as descobertas com os colegas. Trata-se de uma alternativa às cadeiras enfileiradas, estimulando o pensamento crítico e o senso de coletividade. Não ter o professor como o "centro das atenções" a todo momento também é algo novo; é como se todos (discentes e docente) merecessem atenção a partir do momento em que começam a articular, e isso incentiva a busca pelo seu espaço de fala durante as discussões. A sala de tutoria pode ainda comportar tecnologia audiovisual diferenciada, como artefatos de anatomia, lousa digital ou quadro branco, computador e datashow. A disponibilidade desses elementos oferece maiores possibilidades para a aprendizagem, pois conforme descreve Moran

a aprendizagem mais profunda requer espaços de prática frequentes (aprender fazendo) e de ambientes ricos em oportunidades. Por isso, é importante o estímulo multissensorial e a valorização dos conhecimentos prévios dos estudantes para 'ancorar' os novos conhecimentos (MORAN, 2018, p. 3).

\section{O papel do tutor}

O papel do docente tutor no desenvolvimento da sessão tutorial é bastante diferente do papel do docente nas tradicionais aulas expositivas (ALMEIDA; BATISTA, 2013). Sua participação tem influência direta na operacionalidade da sessão tutorial e, portanto, na construção dos objetivos de aprendizagem pelos discentes. Ao longo destes três anos, todos os tutores participaram de forma adequada na abertura e fechamento das situaçõesproblema. De uma forma geral, o autoaprendizado do aluno foi estimulado pela atuação dos professores. Independentemente da formação de origem e/ou capacitação nas metodologias ativas de aprendizagem, a proatividade do docente tutor foi o fator que mais contribuiu para o desenvolvimento do pensamento crítico, do resgate e articulação de 
conceitos/ideias e do estímulo ao raciocínio. Além disso, a autonomia promovida por eles, especialmente no que diz respeito à formação dos objetivos de aprendizagem, fortaleceu a confiança e promoveu um ambiente mais agradável e satisfatório para a aprendizagem dos alunos. Esse apoio permitiu que os estudantes pensassem por si próprios, sem medo de errar, uma vez que o "erro não intencional" faz parte do processo de ensino-aprendizagem (BERBEL, 2011).

Ao contrário do que ocorre nas tradicionais aulas, o professor deixa de ser responsável pela transmissão de conhecimento e passa a ser um facilitador do aprendizado (MARTINS; FALBO NETO; SILVA, 2018). Isso representa um importante passo para a construção de novas aprendizagens pelo discente, pois o docente tutor é o principal responsável por desafiar e/ou encorajar o educando a buscar informações para resolver as situações-problema. Em outras palavras, o aluno é estimulado pelo docente tutor a "pensar fora da caixa" e assumir a responsabilidade por sua aprendizagem.

No entanto, era possível identificar que aqueles com formação específica na área temática da situação-problema incutiam nos estudantes uma maior desenvoltura na abertura e fechamento das sessões tutoriais. Esse domínio de conteúdo permitiu ao docente tutor elaborar questionamentos e elencar saberes com maior facilidade e, portanto, colaborar para que a aprendizagem acontecesse com maior fluidez. Em conjunto, esses resultados sugerem que a atuação do educador não está atrelada à sua formação de origem e/ou capacitação na aplicação das metodologias, mas com a afinidade do tutor com os conteúdos abordados nas situações-problema. As contribuições da ABP na formação dos discentes são resumidamente descritas no Quadro 2. 


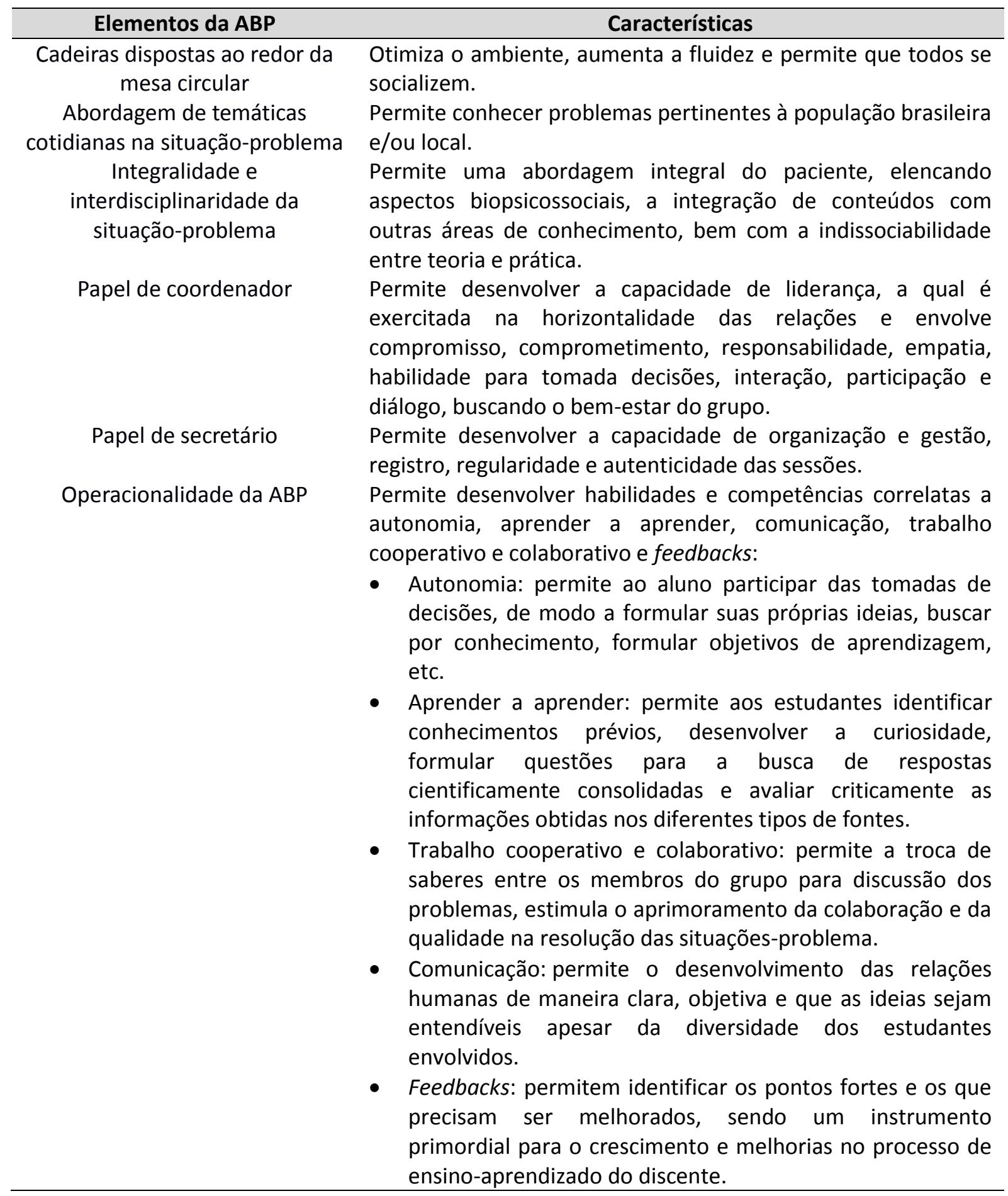

Quadro 2 - Correlação dos elementos que compõem a ABP e suas contribuições para a formação e prática médica

Fonte: elaborado pelos autores, 2019.

\section{CONSIDERAÇÕES FINAIS}

As vivências proporcionadas pela aplicação da $A B P$ resultaram em uma aprendizagem mais autônoma, colaborativa e cooperativa. Isso repercute na autoconfiança do discente e, 
consequentemente, torna-o mais preparado para mobilizar o conhecimento e desenvolver capacidade para gerenciar as informações pertinentes à resolução de problemas reais. Ademais, o desenvolvimento de habilidades e competências correlatas à comunicação proporcionou maior segurança no que diz respeito ao seu posicionamento em outros ambientes, como o contato do aluno com a comunidade em que está inserido e a troca de saberes com profissionais da área da Saúde - e demais áreas - que trabalham nas Unidades de Saúde da Família, hospitais e na própria universidade. Logo, a ABP agrega uma experiência satisfatória, pois o conjunto de elementos que participam do método (operacionais, estruturais e pedagógicos) estimulam o estudante a se preparar de forma mais adequada para enfrentar os desafios propostos pelo mercado de trabalho, o qual exige capacidade de articulação, criatividade, perfil de liderança, trabalho em grupo e empatia, independentemente do público envolvido.

Por fim, destaca-se como limitação do artigo o número reduzido de alunos que relataram sua experiência com o método ABP no curso de Medicina da UNIVASF, campus Paulo Afonso. Contudo, esse tipo de estudo oferece possibilidades para conhecer e compreender uma determinada realidade, e como esta tem influenciado no processo de ensinoaprendizagem desses discentes. Logo, provoca a necessidade de realização de pesquisas mais aprofundadas, que possam contribuir com a produção de conhecimento nas áreas de Educação e Ensino em Saúde.

\section{AGRADECIMENTOS}

Nossos agradecimentos a Luís Gustavo Macedo Sobreira da Silva, estudante de Medicina da Universidade Federal do Vale do São Francisco (UNIVASF), campus Paulo Afonso (Bahia), pela cessão de direitos de uso da imagem da Figura 1B.

\section{REFERÊNCIAS}

ALMEIDA, Enedina Gonçalves; BATISTA, Nildo Alves. Desempenho docente no contexto PBL: essência para aprendizagem e formação médica. Revista Brasileira de Educação Médica, Rio de Janeiro, v. 37, n. 2, p. 192-201, jun. 2013. Disponível em:

https://www.scielo.br/pdf/rbem/v37n2/06.pdf. Acesso em: 2 fev. 2020.

BERBEL, Neusi Aparecida Navas. A problematização e a aprendizagem baseada em problemas: diferentes termos ou diferentes caminhos?. Interface (Botucatu), Botucatu, v. 2, n. 2, p. 139-154, fev. 1998. Disponível em: 
https://www.scielo.br/scielo.php?script=sci_arttext\&pid=S1414-32831998000100008. Acesso em: 14 jun. 2020. DOI: https://doi.org/10.1590/\$1414-32831998000100008.

BERBEL, Neusi Aparecida Navas. As metodologias ativas e a promoção da autonomia de estudantes. Semina: Ciências Sociais e Humanas, Londrina, v. 32, n. 1, p. 25-40, jan./jun. 2011. Disponível em: http://www.uel.br/revistas/uel/index.php/seminasoc/article/view/10326/10999. Acesso em: 15 ago. 2019. DOI: http://dx.doi.org/10.5433/1679-0383.2011v32n1p25.

BOROCHOVICIUS, Eli; TORTELLA, Jussara Cristina Barboza. Aprendizagem Baseada em Problemas: um método de ensino-aprendizagem e suas práticas educativas. Ensaio: Avaliação e Políticas Públicas em Educação, Rio de Janeiro, v. 22, n. 83, p. 263-294, jun. 2014. Disponível em: https://www.scielo.br/pdf/ensaio/v22n83/a02v22n83.pdf. Acesso em: 15 jun. 2020. DOI: http://dx.doi.org/10.1590/\$0104-40362014000200002.

BRASIL. Ministério da Educação. Conselho Nacional de Educação. Câmara de Educação Superior. Resolução CNE/CES no 4, de 7 de novembro de 2001. Diretrizes Curriculares Nacionais do Curso de Graduação em Medicina. Diário Oficial da União: seção 1, Brasília, p. 38, 9 nov. 2001.

BRASIL. Ministério da Educação. Conselho Nacional de Educação. Câmara de Educação Superior. Resolução CNE/CES no 3, de 20 de junho de 2014. Diretrizes Curriculares Nacionais do Curso de Graduação em Medicina. Diário Oficial da União: seção 1, Brasília, p. 8-11, 2014.

CEZAR, Pedro Henrique Netto; GUIMARÃES, Francisco Tavares; GOMES, Andréia Patrícia; ROÇAS, Giselle; SIQUEIRA-BATISTA, Rodrigo. Transição paradigmática na educação médica: um olhar construtivista dirigido à aprendizagem baseada em problemas. Revista Brasileira de Educação Médica, Rio de Janeiro, v. 34, n. 2, p. 298-303, jun. 2010. Disponível em: https://www.scielo.br/pdf/rbem/v34n2/a15v34n2.pdf. Acesso em: 26 ago. 2019. DOI: https://doi.org/10.1590/S0100-55022010000200015.

COSTA, José Roberto Bittencourt; ROMANO, Valéria Ferreira; COSTA, Rosane Rodrigues; GOMES, Andréia Patrícia; SIQUEIRA-BATISTA, Rodrigo. Active teaching-learning methodologies: medical students' views of problem-based learning. Revista Brasileira de Educação Médica, Rio de Janeiro, v. 35, n. 1, p. 13-19, mar. 2011. Disponível em: https://www.scielo.br/scielo.php?script=sci_arttext\&pid=S0100-55022011000100003. Acesso em: 15 jun. 2020. DOI: https://doi.org/10.1590/S0100-55022011000100003.

DIESEL, Aline; BALDEZ, Alda Leila Santos; MARTINS, Silvana Neumann. Os princípios das metodologias ativas de ensino: uma abordagem teórica. Revista Thema, Pelotas, v. 14, n. 1, p. 268-288, 2017. Disponível em: http://periodicos.ifsul.edu.br/index.php/thema/article/view/404/295. Acesso em: 05 set. 2019. DOI: http://dx.doi.org/10.15536/thema.14.2017.268-288.404.

FARIAS, Pablo Antonio Maria de; MARTIN, Ana Luiza de Aguiar Rocha; CRISTO, Cinthia Sampaio. Aprendizagem ativa na Educação em Saúde: percurso histórico e aplicações. Revista Brasileira de Educação Médica, Rio de Janeiro, v. 39, n. 1, p. 143-150, mar. 2015. 
Disponível em: https://www.scielo.br/pdf/rbem/v39n1/1981-5271-rbem-39-1-0143.pdf. Acesso em: 20 ago. 2019. DOI: https://doi.org/10.1590/1981-52712015v39n1e00602014.

GOMES, Romeu; BRINO, Rachel de Faria; AQUILANTE, Aline Guerra; AVÓ, Lucimar Retto da Silva de. Aprendizagem Baseada em Problemas na formação médica e o currículo tradicional de Medicina: uma revisão bibliográfica. Revista Brasileira de Educação Médica, Rio de Janeiro, v. 33, n. 3, p. 444-451, set. 2009. Disponível em:

https://www.scielo.br/scielo.php?script=sci_arttext\&pid=S010055022009000300014\&Ing=en\&nrm=iso. Acesso em: 15 jun. 2020. DOI: https://doi.org/10.1590/S0100-55022009000300014.

GOMES, Andréia Patrícia; REGO, Sergio. Transformação da educação médica: é possível formar um novo médico a partir de mudanças no método de ensino-aprendizagem?. Revista Brasileira de Educação Médica, Rio de Janeiro, v. 35, n. 4, p. 557-566, dez. 2011. Disponível em: https://www.scielo.br/scielo.php?pid=S0100-

$55022011000400016 \&$ script=sci_abstract\&tlng=pt. Acesso em: 10 jun. 2020. DOI: https://doi.org/10.1590/S0100-55022011000400016.

IGARASHI, Fernanda de Oliveira; HAMAMOTO, Cássia Galli; SANTOS, Ione Ferreira. Processo ensino-aprendizagem: compreensão de estudantes de um curso de Medicina sobre a Aprendizagem Baseada em Problemas. Ciaiq - Investigação Qualitativa em Educação, São Paulo, v. 1, n. 1, p. 772-781, 2018. Trabalho apresentado no 70 Congresso Ibero-Americano em Investigação Qualitativa (CIAIQ), 2018, Fortaleza. Disponível em: https://proceedings.ciaiq.org/index.php/ciaiq2018/article/view/1706. Acesso em: 27 ago. 2019.

MACEDO, Kelly Dandara da Silva; ACOSTA, Beatriz Suffer; SILVA, Ethel Bastos da; SOUZA, Neila Santini de; BECK, Carmem Lúcia Colomé; SILVA, Karla Kristiane Dames da. Active learning methodologies: possible paths to innovation in health teaching. Escola Anna Nery, Rio de Janeiro, v. 22, n. 3, 2018. Disponível em: https://www.scielo.br/scielo.php?script=sci_arttext\&pid=S1414-81452018000300704. Acesso em: 8 dez. 2019. DOI: https://doi.org/10.1590/2177-9465-ean-2017-0435.

MAMEDE, S.; PENAFORTE, J. C. Aprendizagem baseada em problemas: anatomia de uma nova abordagem educacional. Fortaleza: Hucitec, 2001.

MARTINS, Antonio Carlos; FALBO NETO, Gilliatt; SILVA, Fernando Antonio Menezes da. Características do tutor efetivo em ABP: uma revisão de literatura. Revista Brasileira de Educação Médica, Brasília, v. 42, n. 1, p. 105-114, jan. 2018. Disponível em: https://www.scielo.br/pdf/rbem/v42n1/0100-5502-rbem-42-01-0105.pdf. Acesso em: 2 fev. 2020. DOI: https://doi.org/10.1590/1981-52712018v42n1rb20160100.

MILLAN, Laís Pereira Bueno; SEMER, Beatriz; RODRIGUES, José Mauro da Silva; GIANINI, Reinaldo José. Traditional learning and problem-based learning: self-perception of preparedness for internship. Revista da Associação Médica Brasileira, São Paulo, v. 58, n. 5, p. 594-599, out. 2012. Disponível em: https://www.scielo.br/scielo.php?pid=S0104- 
42302012000500018\&script=sci_arttext\&tlng=en. Acesso em: 15 jun. 2020. DOI: https://doi.org/10.1590/S0104-42302012000500018.

MORAES, Magali Aparecida Alves de; MANZINI, Eduardo José. Concepções sobre a aprendizagem baseada em problemas: um estudo de caso na Famema. Revista Brasileira de Educação Médica, Rio de Janeiro, v. 30, n. 3, p. 125-135, dez. 2006. Disponível em: https://www.scielo.br/scielo.php?pid=S010055022006000300003\&script=sci_abstract\&tIng=pt. Acesso em: 10 jun. 2020. DOI: https://doi.org/10.1590/S0100-55022006000300003.

MORAN, José. Metodologias ativas para uma aprendizagem profunda. In: BACICHI, Lilian; MORAN, José (org.). Metodologias ativas para uma educação inovadora: uma abordagem teórico-prática. Porto Alegre: Penso, 2018.

OLIVEIRA, Bruno Luciano Carneiro Alves de; LIMA, Sara Fiterman; PEREIRA, Marina Uchoa Lopes; PEREIRA JÚNIOR, Gerson Alves. Evolução, distribuição e expansão dos cursos de Medicina no Brasil (1808-2018). Trabalho, Educação e Saúde, Rio de Janeiro, v. 17, n. 1, p. 120, 2019. Disponível em: https://www.scielo.br/pdf/tes/v17n1/0102-6909-tes-17-1e0018317.pdf. Acesso em: 22 ago. 2019. DOI: https://doi.org/10.1590/1981-7746-sol00183.

PIMENTEL, Nara. As Tecnologias de Informação e Comunicação (TIC) no ensino superior: a utopia da inovação pedagógica e da modernização. Revista de Educação Pública, Cuiabá, v. 25, n. 59/2, p. 476-501, maio/ago. 2016. Disponível em:

https://periodicoscientificos.ufmt.br/ojs/index.php/educacaopublica/article/view/3831. Acesso em: 14 ago. 2019. DOI: https://dx.doi.org/10.29286/rep.v25i59/2.3831.

SAKAI, Marcia Hiromi; LIMA, Gerson Zanetta de. PBL: uma visão geral do método. Olho Mágico, Londrina, v. 2, n. 5/6, p. 24-30, nov. 1996.

SMOLKA, Maria Lúcia Rebello Marra; GOMES, Andréia Patrícia; SIQUEIRA-BATISTA, Rodrigo. Autonomia no Contexto Pedagógico: Percepção de Estudantes de Medicina acerca da Aprendizagem Baseada em Problemas. Revista Brasileira de Educação Médica, Rio de Janeiro, v. 38, n. 1, p. 5-14, mar. 2014. Disponível em:

https://www.scielo.br/scielo.php?pid=S0100-

55022014000100002\&script=sci_abstract\&tlng=pt. Acesso em: 27 ago. 2019. DOI: https://doi.org/10.1590/S0100-55022014000100002.

SOUZA, Laura Augusto de; FRANCO, Sergio Roberto Kieling. Adaptação do jovem à universidade e o impacto no bem-estar psicológico do estudante de Licenciatura em Pedagogia. Saúde em Redes, Porto Alegre, v. 4, n. 2, p. 59-69, 2018. Disponível em: http://revista.redeunida.org.br/ojs/index.php/rede-unida/article/view/883. Acesso em: 8 nov. 2019.

SOUZA, S. C.; DOURADO, L. Aprendizagem Baseada em Problemas (ABP): um método de aprendizagem inovador para o ensino educativo. HOLOS, v. 5, p. 182-200, out. 2015. Disponível em: http://www2.ifrn.edu.br/ojs/index.php/HOLOS/article/viewFile/2880/1143. Acesso em: 14 jun. 2020. DOI: https://doi.org/10.15628/holos.2015.2880. 
TAKENAMI, Iukary Oliveira; PALÁCIO, Maria Augusta Vasconcelos; ANDRADE, Wellen Zane Nunes; CANSANÇÃO, Isaac Farias. Uso das metodologias ativas de aprendizagem em instituições de ensino médico no Nordeste brasileiro. Revasf, Petrolina v. 8, n. 17, p. 22-38, dez. 2018. Disponível em:

https://www.periodicos.univasf.edu.br/index.php/revasf/article/view/239. Acesso em: 12 set. 2019.

TEIXEIRA, Luciana Scapin; ALMEIDA, Leandro; AGUILAR-DA-SILVA, Rinaldo. Mudança curricular e de métodos pedagógicos: impacto vivenciado por estudantes de Medicina. Revista de Estudios e Investigación En Psicología y Educación, v. 5, n. 1, p. 19-28, 2018. Disponível em:

http://repositorium.sdum.uminho.pt/bitstream/1822/56996/1/Mudan\%C3\%A7a\%20curricul ar\%20e\%20de\%20m\%C3\%A9todos\%20pedag\%C3\%B3gicos_Impacto\%20vivenciado\%20por\% 20estudantes\%20de\%20Medicina.pdf. Acesso em: 20 nov. 2019. DOI:

https://doi.org/10.17979/reipe.2018.5.1.3349.

TORRES, Vânia; SAMPAIO, Cristina Andrade; CALDEIRA, Antônio Prates. Ingressantes de cursos médicos e a percepção sobre a transição para uma aprendizagem ativa. Interface (Botucatu), Botucatu v. 23, p. 1-16, 2019. Disponível em:

https://www.scielo.br/scielo.php?pid=S1414-

32832019000100203\&script=sci_arttext\&tIng=pt. Acesso em: 20 nov. 2019. DOI: http://dx.doi.org/10.1590/interface.170471.

TSUJI, Hissach; AGUILAR-DA-SILVA, Rinaldo. Relato de Experiência de Um Novo Modelo Curricular: Aprendizagem Baseada em Problemas, Implantada na Unidade Educacional do Sistema Endocrinológico na 2a Série do Curso Médico da Faculdade de Medicina de Marília FAMEMA. Arquivos Brasileiros de Endocrinologia \& Metabologia, São Paulo, v. 48, n. 4, p. 535-543, ago. 2004. Disponível em: https://www.scielo.br/scielo.php?pid=S000427302004000400015\&script=sci_abstract\&tIng=pt. Acesso em: 15 jun. 2020. DOI: https://doi.org/10.1590/S0004-27302004000400015.

UNIVERSIDAde FEDERAL DO VALE DO SÃO FRANCISCO. Projeto Político Pedagógico do Curso de Graduação em Medicina. Paulo Afonso, BA: UNIVASF, 2017. Disponível em: http://portais.univasf.edu.br/medicina-pa/medicina-pa/documentos-e-normas/ppcmedicina-univasf-campus-paulo-afonso-ba.pdf. Acesso em: 20 jun. 2019. 


\section{Maylon Wellik dos Santos Carvalho}

Graduando em Medicina pela Universidade Federal do Vale do São Francisco (UNIVASF), campus Paulo Afonso, Bahia.

mwscmedicina@outlook.com

\section{Wellen Zane Nunes Andrade}

Graduanda em Medicina pela Universidade Federal do Vale do São Francisco (UNIVASF), campus Paulo Afonso, Bahia.

wellenzandrade@gmail.com

\section{Isaac Farias Cansanção}

Doutor em Biotecnologia pela Universidade Federal do Ceará (RENORBIO/UFC), professor adjunto do Colegiado de Medicina da Universidade Federal do Vale do São Francisco (UNIVASF), campus Paulo Afonso, Bahia e professor permanente do Programa de PósGraduação em Extensão Rural da UNIVASF.

isaac.farias@univasf.edu.br

\section{Maria Augusta Vasconcelos Palácio}

Doutora em Educação em Ciências e Saúde pela Universidade Federal do Rio de Janeiro (UFRJ), professora adjunta do Colegiado de Medicina da Universidade Federal do Vale do São Francisco (UNIVASF), campus Paulo Afonso, Bahia.

augusta.palacio@univasf.edu.br

\section{lukary Takenami}

Doutora em Biotecnologia em Saúde e Medicina Investigativa pelo Instituto Gonçalo Moniz (IGM), Fundação Oswaldo Cruz (Fiocruz). Professora adjunta do Colegiado de Medicina da Universidade Federal do Vale do São Francisco (UNIVASF), campus Paulo Afonso, Bahia. iukary.takenami@univasf.edu.br 